\title{
Barriers to successful dietary control among pregnant women with phenylketonuria
}

Amanda Savage Brown, PhD ${ }^{1,2}$, Paul M. Fernhoff, $M D^{4}$, Susan E. Waisbren, PhD ${ }^{5}$, Dianne M. Frazier, PhD ${ }^{6}$, Rani Singh, PhD ${ }^{4}$, Fran Rohr, $R D^{5}$, Jill M. Morris, PhD ${ }^{1,2}$, Aileen Kenneson, PhD ${ }^{3}$, Pia MacDonald, PhD ${ }^{1,7}$, Marta Gwinn, $\mathrm{MD}^{2}$, Margaret Honein, $P h D^{3}$, and Sonja A. Rasmussen, $M D^{3}$

Purpose: The teratogenic effects of maternal PKU are preventable, yet affected babies continue to be born. This study's purpose was to identify barriers to successful dietary control among pregnant women with PKU. Methods: An interview-based study was conducted of women with PKU who were known to metabolic disease clinics in three states and pregnant during 1998 to 2000. Medical records were used to document timing of metabolic control. Results: Of 24 women in the study, only 8 (33\%) initiated the diet before pregnancy. Of 22 medical records received, only 12 (55\%) indicated control of blood phenylalanine levels before 10 weeks' gestation. Risk factors for late dietary control included young age and belief that treatment costs complicated the diet. Although all of the women expressed confidence in the metabolic clinic staff, few perceived their obstetricians were knowledgeable about the maternal PKU diet. Of 13 women enrolled in state-based assistance programs, 9 (69\%) reported proof of pregnancy was required for eligibility. Many women using private insurance reported their insurers were unwilling to pay for medical foods. When the data were stratified according to state of residence, differences were observed in the rate of live-born infants, prepregnancy medical food use, average travel time to the metabolic clinic, and gestational week when metabolic control was achieved. Conclusion: Our study's findings may be used to target educational messages to women with PKU and to direct future research directions. For example, obstetric knowledge of maternal PKU needs further evaluation. Discrepancies should be resolved between maternal PKU medical recommendations and the policies of third party-payers. The disparities in financial assistance and services available to pregnant women with PKU residing in different states should be examined further. Genet $\mathbf{M e d}$ 2002:4(2):84-89.

Key Words: phenylketonuria, maternal phenylketonuria, metabolic disorder, mental retardation, medical foods, diet

Phenylketonuria (PKU) is an inborn error of metabolism caused by deficiency in the enzyme phenylalanine hydroxylase resulting in an inability to convert the amino acid phenylalanine to tyrosine. High concentrations of blood phenylalanine cause mental retardation, which is preventable through a phenylalanine-restricted diet consisting of a special amino acidbased metabolic formula and severe restriction of protein-containing foods. Because the diet is most effective if initiated within the first few days of life, PKU served as the model for

From the ${ }^{I}$ Epidemic Intelligence Service, Division of Applied Public Health Training, Epidemiology Program Office, ${ }^{2}$ Office of Genetics and Disease Prevention, National Center for Environmental Health, and ${ }^{3}$ National Center on Birth Defects and Developmental Disabilities, Centers for Disease Control and Prevention, Atlanta, Georgia; ${ }^{4}$ Emory University, Atlanta, Georgia; ${ }^{5}$ Children's Hospital, Boston, Massachusetts; ${ }^{6}$ University of North Carolina, Chapel Hill, North Carolina; and ${ }^{7}$ North Carolina Department of Health and Human Services, Division of Public Health, Epidemiology Section, Raleigh, North Carolina.

Amanda Savage Brown, PhD, Centers for Disease Control and Prevention, National Center on Birth Defects and Developmental Disabilities, 4770 Buford Highway, MS F-45, Atlanta, GA 30341.

Received: October 17, 2001.

Accepted: December 17, 2001. disorders diagnosed presymptomatically through newborn screening programs. All states now include PKU in their newborn screening panels.

The current medical recommendation for people with PKU is lifelong maintenance of a phenylalanine-restricted diet. ${ }^{1}$ Originally, it was believed that children with PKU could safely discontinue their diet when brain growth was completed. ${ }^{2}$ However, in the 1980s, research indicated that the high blood phenylalanine level in people with PKU who have discontinued their diets often leads to a decrease in IQ, learning disabilities, behavioral problems, and some reports of neurologic complications. ${ }^{2-5}$ Additional risks of diet discontinuation exist when women with PKU whose blood phenylalanine levels are not controlled become pregnant. More than $90 \%$ of infants born of such pregnancies have mental retardation, and a high incidence of microcephaly, low birth weight, and congenital heart disease also occurs. ${ }^{6}$ This finding is due to teratogenic effects of high maternal blood phenylalanine levels.

The risks to the fetus associated with maternal PKU can be greatly reduced, even avoided, if dietary control is achieved before conception and maintained throughout pregnancy. ${ }^{6-14}$ 
Recommendations for women with PKU who have discontinued diet and are contemplating pregnancy are to begin dietary phenylalanine restriction 7 months before conception through consumption of medical foods, have their blood phenylalanine levels monitored 1 to 2 times per week and maintained between 2 and $6 \mathrm{mg} / \mathrm{dL}(120-360 \mu \mathrm{mol} / \mathrm{L})$, and receive treatment from a metabolic clinic with professional staff members that specialize in the management of PKU.1,15-17

An estimated 3 to 4 thousand reproductive-aged women with PKU live in the United States, and several hundred more women enter this cohort each year. ${ }^{15,18}$ Women with PKU often present at the metabolic clinic several weeks pregnant and not following a prescribed diet. Despite the known and preventable risks for adverse pregnancy outcomes associated with maternal PKU, affected babies continue to be born. Thus the net benefit of preventing mental retardation in infants identified with PKU through newborn screening programs may be reduced as women with PKU have babies with mental retardation. ${ }^{19,20}$ The objective of the present study was to identify the barriers to successful dietary control of blood phenylalanine levels among pregnant women with PKU.

\section{METHODS}

The following methods were approved by the Centers for Disease Control and Prevention's Institutional Review Board. For inclusion in the study, women had to meet the following criteria: have classic PKU or hyperphenylalaninemia, be at least 18 years of age, and have been pregnant during 1998 to 2000 . Women meeting these criteria were eligible to participate in the study regardless of pregnancy outcome or dietary treatment. Because no registries exist for maternal PKU-affected pregnancies, women were ascertained through metabolic clinics that manage PKU patients. Women were recruited from three states with metabolic clinic staff who were willing to contact their patients about the study. Each woman who agreed to be in the study was interviewed in person when possible; otherwise, a telephone interview was conducted. Women were interviewed using a structured questionnaire with questions about the following: general demographics; medical, pregnancy, and birth control histories; financial coverage issues for medical care and diet-related expenses; and social and professional support.

Medical records were requested to document timing of diet initiation, metabolic control, and pregnancy outcome. Information from the medical records was used to group the women according to timing of metabolic control: blood phe levels 2 to $6 \mathrm{mg} / \mathrm{dL}(120-360 \mu \mathrm{mol} / \mathrm{L})$ before or after 10 weeks' gestation. Ten weeks was chosen as the stratification point because babies born to women whose blood phenylalanine levels are in control before 10 weeks have lower rates of abnormalities than do babies born to women who achieve control later in gestation. ${ }^{14,17}$ Separating women into these two groups allowed identification of potential risk factors associated with poor metabolic control. Associations between variables of interest and timing of metabolic control were measured by Fisher's exact test, reporting risk ratios (RRs) and 95\% confidence intervals (CIs). Multivariable analyses were not conducted because of the small study sample size.

\section{RESULTS}

Staff at the clinics indicated that 30 women met the study criteria; however, two were lost to clinic follow-up. Of the remaining 28 women, 24 were interviewed ( 17 in person and 7 by telephone) and 4 were unable to be reached. Two women indicated that they had hyperphenylalaninemia. Demographic characteristics of the study population and pregnancy histories are shown in Tables 1 and 2, respectively. Only one woman had remained on the diet throughout adulthood; the other 23 discontinued the diet earlier in life. Before trying to reinitiate diet because of a pregnancy, the range of time off diet for these women ranged from 6 to 24 years (mean, 16 years).

The remainder of the interview retrospectively assessed each woman's adherence to medical recommendations before, during, and after her index pregnancy. Twenty-two (92\%) women attempted to return to diet either before $(N=8)$ or during $(N$ $=14$ ) pregnancy. Of the two who did not return to diet, one did not receive any dietary management, and the other woman miscarried (at 6-8 weeks' gestation) before she initiated the diet. Sixteen $(67 \%)$ women were not using medical foods at the time of conception. Formula use before conception was more commonly reported among the 11 women who were trying to conceive (RR, 3.5; 95\% CI, 1.6, 10.2). Use of specially modified, low-protein foods was reported only among women who were trying to conceive. No difference in avoidance of highprotein foods was observed between women who were or were not trying to conceive. The women who intended to become pregnant appeared more likely to adhere to the recommended prepregnancy diet-related behaviors, e.g., resuming medical foods use and meeting with a dietitian (Table 3). Still, even among women who planned their pregnancy, one third to half did not report adherence to this subset of prepregnancy dietrelated recommendations. Sixteen (67\%) women reported maintaining a daily food-intake record during pregnancy. Nineteen (79\%) women reported they monitored their blood

\section{Table 1}

Demographics and diet-related information of study participants $(n=24)$

\begin{tabular}{ll}
\hline Variable & $n(\%)$ \\
\hline Age (years) & $22-38$ \\
Range & 29 \\
Mean & $18(75)$ \\
Married & $23(96)$ \\
Caucasian & \\
Education & $12(50)$ \\
$\leq$ High school & $12(50)$ \\
$>$ High school & \\
\hline
\end{tabular}


Table 2

Pregnancy histories of study participants

\begin{tabular}{lllll}
\hline & \multicolumn{2}{l}{ Lifetime $(n=51)$} & & \multicolumn{2}{c}{ Index $(n=24)$} \\
\cline { 2 - 3 } \cline { 5 - 6 } Pregnancy & $n$ & & $n$ & $(\%)$ \\
\hline
\end{tabular}

Outcome

\begin{tabular}{lrrrl} 
Live birth & 28 & $(55)$ & 18 & $(75)$ \\
Miscarriage & 15 & $(29)$ & 4 & $(17)$ \\
Termination & 8 & $(16)$ & 2 & $(8)$ \\
Planned & 18 & $(35)$ & 11 & $(46)$ \\
\hline
\end{tabular}

Lifetime pregnancies include all pregnancies experienced by each woman. Index pregnancy is the most recent pregnancy.

Table 3

Prepregnancy dietary management among women with PKU by pregnancy intendedness

\begin{tabular}{|c|c|c|c|c|}
\hline \multirow[b]{2}{*}{ Management } & \multicolumn{2}{|c|}{$\begin{array}{l}\text { Intended } \\
(n=11)\end{array}$} & \multicolumn{2}{|c|}{$\begin{array}{l}\text { Not intended } \\
\quad(n=13)\end{array}$} \\
\hline & $n$ & $(\%)$ & $n$ & $(\%)$ \\
\hline Met with a dietitian & 7 & $(64)$ & 1 & (8) \\
\hline Used formula & 7 & $(64)$ & 1 & (8) \\
\hline Used low-protein foods & 5 & $(45)$ & 0 & $(0)$ \\
\hline Avoided high-protein foods & 6 & $(55)$ & 4 & $(31)$ \\
\hline
\end{tabular}

Intendedness was determined by asking the participant: "Before your most recent pregnancy, were you trying to get pregnant?"

phenylalanine levels at least once per week while pregnant. The average travel time to the clinic was 1.75 hours (range, 15 minutes to 5 hours).

Financial issues potentially affecting a woman's ability to adhere to the diet were also examined. All but one woman reported receiving financial assistance with various treatmentand/or pregnancy-related costs either through private insurance, public assistance (e.g., Medicaid and Women, Infants, and Children programs), or both (Table 4). Of the women who reported assistance with the costs of clinic visits, nearly equal numbers used public assistance and private insurance. Assis- tance with the costs of medical foods was more often reported through public assistance programs than through private insurance. Of the 13 women who used public assistance, $9(69 \%)$ reported that proof of pregnancy was required for them to receive services.

Fourteen $(58 \%)$ women reported working at paying jobs during their pregnancy. Two of these women quit their jobs to better follow their prescribed diets; and another switched jobs because she was unable to follow her diet while working in her previous position. None of these women reported problems acquiring time off from work to attend clinic visits; however, one woman reported she could not financially afford to request the time off required to drive to the nearest metabolic clinic, which was a 3.5 -hour drive each way.

Emotional and psychosocial factors that might have affected a woman's ability to adhere to the diet were evaluated as well. Of the 20 women who reported following the diet before and/or during their most recent pregnancy, 17 (85\%) believed they had received sufficient amounts of support from family and friends. Most women (88\%) reported that talking with another woman with PKU during pregnancy would also be helpful. However, fewer than half of the women $(N=11)$ reported participation in an educational or support program specific to maternal PKU where they are able to meet peers (e.g., a summer camp). Reasons reported for not participating included prohibitive costs associated with camps and time off from work required to attend.

Twenty-three (96\%) women believed the diet was necessary for women with PKU to have healthy babies; the remaining woman believed the importance of the diet was overstated. All of the 21 women who were in contact with the metabolic staff before or during pregnancy believed the clinic staff informed them of the risks of maternal PKU before becoming pregnant. Similarly, all of these women reported that the metabolic clinic staff was knowledgeable about the maternal PKU diet. In contrast, only eight $(33 \%)$ women believed their obstetricians were knowledgeable about the maternal PKU diet and the special concerns related to pregnancies in women with PKU. Two women reported their obstetricians served as their only care provider during pregnancy. Although PKU was included in each of their prenatal medical records, neither woman was

Table 4

Reported use of private insurance or public assistance for dietary management costs among women with PKU during pregnancy

\begin{tabular}{|c|c|c|c|c|c|c|}
\hline \multirow{3}{*}{$\begin{array}{l}\text { Type of } \\
\text { assistance }\end{array}$} & \multicolumn{6}{|c|}{ Women who reported assistance with costs of } \\
\hline & \multicolumn{2}{|c|}{$\begin{array}{l}\text { Clinic visits } \\
(n=20)\end{array}$} & \multicolumn{2}{|c|}{$\begin{array}{l}\text { Formula } \\
(n=20)\end{array}$} & \multicolumn{2}{|c|}{$\begin{array}{l}\text { Low-protein foods } \\
\quad(n=12)\end{array}$} \\
\hline & $n$ & $(\%)$ & $n$ & $(\%)$ & $n$ & $(\%)$ \\
\hline Public & $10^{a}$ & $(50)$ & 13 & $(65)$ & 6 & $(50)$ \\
\hline Private & $12^{a}$ & $(60)$ & 6 & $(30)$ & 2 & $(17)$ \\
\hline Other $^{b}$ & 0 & & 1 & (5) & 4 & (33) \\
\hline
\end{tabular}

${ }^{a}$ Two women reported using both public assistance and private insurance at the clinic.

${ }^{b}$ Family members or friends. 
referred to a metabolic clinic, nor were their blood phenylalanine levels regularly monitored. Both women had live-born infants with microcephaly.

Twenty-two medical records were received for use in documenting the timing of metabolic control (defined as blood phenylalanine $2-6 \mathrm{mg} / \mathrm{dL}$ ). To identify potential risk factors associated with poor metabolic control, women were grouped according to when they achieved metabolic control: before $(N$ $=12)$ or after $(N=10) 10$ weeks' gestation. Factors associated with late metabolic control appear to be age $<25$ years (RR, 8.4; 95\% CI, 1.9, 147.8) and believing that the costs of treatment add to the complications of the diet (RR, $4.2 ; 95 \% \mathrm{CI}, 1.4$, 23.3). Other factors for which the risk was increased were having a high school education or less and dependence on state assistance programs (Table 5).

Stratifying the data by the women's state of residence revealed that women in state $\mathrm{C}$ had the lowest rate of live-born infants among their pregnancies, lowest use of medical foods before pregnancy, fewest women achieving metabolic control before 10 weeks' gestation, and longest commutes to the clinic (Table 6). Women in states A and B had access to capsules (as an alternative mode of formula delivery), but because of difficulties in preparing and time involved in swallowing the capsules, only $50 \%$ of the women in state A and $25 \%$ of the women in state B used them. No woman in state C reported use of capsules, and only one was aware of them as an option.

Finally, $17(71 \%)$ of the women were not using medical foods at the time of the interview. The most frequently reported reason for discontinuing formula use upon completion of pregnancy was the unpleasant taste $(65 \%)$. Other reasons included the belief that there was no reason to follow the diet unless pregnant, difficulties in preparing the formula, and desire to eat the same as others.

\section{DISCUSSION}

This interview-based, multistate study of the barriers to successful dietary control among pregnant women with PKU highlighted several common barriers regardless of the woman's state of residence. Reported treatment regimen-related barriers included the adverse taste of the formula, long commutes to the clinic, and the need to take time off from work without pay to attend multiple clinic visits. Psychosocial and emotional issues included a desire to interact with other women with PKU, lack of confidence in obstetric knowledge about maternal PKU, and poor adherence to prepregnancy recommendations, despite awareness of maternal PKU pregnancy-related risks.

Many economic and health-care system issues were identified, including infrequent assistance with the costs of formula and low-protein foods by private insurers, despite the passage of the US Public Law (Publ L) 100-290 defining the formula as a medical food. ${ }^{21}$ Compared with private insurance, public assistance programs provided more coverage for the cost of the medical foods, clinic visits, and low-protein foods. Women dependent on public assistance programs were, however, less likely to achieve metabolic control before 10 weeks' gestation. Although these findings seem inconsistent, they most likely reflect that many of the women enrolled in public assistance programs were younger and less educated, factors associated with late metabolic control. The interaction of these variables is difficult to measure because of the small numbers. However, they may provide clues about how to best target educational messages to these women.

Discrepancies in access to services among the women receiving care in these three states may indicate potential disparities in services available to women with PKU across the country. Although the cost of the formula for minors is covered by all states, these coverage policies change for adults. Some states do not have adequate funding or programs to provide medical foods for pregnant women, and the majority does not assist with the costs of low protein foods. ${ }^{22}$ As seen in the present study, women who believe the cost of the diet complicates their ability to follow the diet are less likely to achieve adequate metabolic control. Thus a woman's ability to adhere to the diet and have a successful pregnancy outcome may depend on the state in which she resides.

These findings suggest several ways to reduce barriers to successful dietary control that may improve pregnancy outcomes for women with PKU. As observed in the study population, women with PKU often lose contact with metabolic clinics or only interact with the clinic once they are pregnant; hence, efforts to advise women to plan their pregnancies, return to diet before conception, and stay on the diet for life

Table 5

Unadjusted, univariate analysis of differences between women with PKU who achieved metabolic control before vs. after 10 weeks' gestation

\begin{tabular}{|c|c|c|c|c|c|c|}
\hline \multirow[b]{3}{*}{ Variable } & \multicolumn{4}{|c|}{ Metabolic control (blood phe level 2-6 mg/dL) } & \multirow[b]{3}{*}{ Risk ratio } & \multirow[b]{3}{*}{$95 \% \mathrm{CI}$} \\
\hline & \multicolumn{2}{|c|}{ Before $(n=12)$} & \multicolumn{2}{|c|}{ After $(n=10)$} & & \\
\hline & $n$ & $(\%)$ & $n$ & $(\%)$ & & \\
\hline Age $\leq 25$ years & 1 & $(8)$ & 7 & $(70)$ & 8.4 & $(1.9,147.8)$ \\
\hline $\begin{array}{l}\text { Believed treatment costs } \\
\text { add to difficulties of diet }\end{array}$ & 2 & $(17)$ & 7 & $(70)$ & 4.2 & $(1.4,23.3)$ \\
\hline Education $\leq$ high school & 3 & $(25)$ & 7 & $(70)$ & 2.8 & $(1.1,10.3)$ \\
\hline Used public assistance & 4 & (33) & 8 & $(80)$ & 2.4 & $(1.1,6.9)$ \\
\hline
\end{tabular}


Table 6

Differences among women with PKU residing in three states

\begin{tabular}{|c|c|c|c|c|c|c|c|c|c|c|}
\hline \multirow[b]{2}{*}{ State $(n)$} & \multicolumn{2}{|c|}{$\begin{array}{l}\text { Index pregnancy: } \\
\text { live-born infants }\end{array}$} & \multicolumn{2}{|c|}{$\begin{array}{c}\text { Prepregnancy } \\
\text { formula use }\end{array}$} & \multicolumn{2}{|c|}{ Capsule use } & \multicolumn{2}{|c|}{ Travel time (hours) } & \multicolumn{2}{|c|}{$\begin{array}{l}\text { Metabolic control } \\
\text { (blood phe level } \\
2-6 \mathrm{mg} / \mathrm{dL} \text { ) } \\
<10 \text { weeks }\end{array}$} \\
\hline & $n$ & $(\%)$ & $n$ & $(\%)$ & $n$ & $(\%)$ & Range & Average & $n$ & $(\%)^{a}$ \\
\hline A (6) & 5 & $(83)$ & 2 & (33) & 3 & $(50)$ & $0.25-2.5$ & 1 & 3 & $(50)$ \\
\hline B (8) & 7 & $(88)$ & 5 & $(63)$ & 2 & $(25)$ & $0.25-1.5$ & 1 & 6 & $(86)$ \\
\hline $\mathrm{C}(10)$ & 6 & $(60)$ & 1 & $(10)$ & 1 & (10) & $0.25-5$ & 2.75 & 3 & (33) \\
\hline
\end{tabular}

${ }^{a}$ Percentages reflect denominator of medical records received from each state $(A=6, B=7, C=9)$.

should extend beyond the metabolic clinic into the offices of obstetricians, family practitioners, and pediatricians. Knowledge and practices of obstetricians regarding maternal PKU should be evaluated. Although the present study did not formally assess obstetricians' knowledge about maternal PKU, the lack of referrals by obstetricians to a metabolic clinic of two women is of concern. Programs that provide educational forums in which adolescents and women with PKU interact increase knowledge about diet and disease and improve metabolic control among participants. ${ }^{23,24}$ These programs may need further development and funding to increase their practical and financial accessibility. Home visitation programs, such as the Resource Mother's Program, are effective in achieving earlier metabolic control during pregnancy. ${ }^{25}$ In-home (or at-work) assistance (e.g., a visiting nurse to collect blood, review food diary, assist with medical foods or food preparation) would address the difficulties experienced by many women facing long commutes and the resultant loss of income from missing work to attend their regular metabolic clinic appointments; however, these programs may be less practical in states where the population is not concentrated in one area. State laws should be evaluated to determine the magnitude of disparities in financial assistance and services available to pregnant women with PKU and to identify the most cost-effective approach. Public health programs that identify and treat infants with PKU should develop ways to improve long-term follow-up and consider maternal PKU when evaluating impact of newborn screening programs.

The findings from this study are subject to the following limitations. The sample size was small and consisted mostly of women who received care from metabolic clinics that manage PKU. The barriers identified among the study population are likely to be a subset of those experienced by women without access to metabolic clinics. In some states, women with PKU may have to seek care from a local health department and rely entirely on an obstetrician or family practitioner for pregnancy management. Also, at the time of the interview most of the women were not following their diets; people with PKU who are not on diet may have difficulties with concentration and memory, so the accuracy of the responses may be compromised.
Despite these limitations, this study provides an opportunity to better understand the growing issue of maternal PKU and its potential to undermine the effectiveness of newborn screening programs in preventing PKU-associated mental retardation. It also provides insight into potential areas for future study of the important and preventable condition of maternal PKU.

As technologic advances, such as tandem mass spectrometry, increase the number of conditions included in newborn screening programs, maternal PKU may become one of several diseases with such "second-generation effects." This potential further highlights the importance of successfully addressing the challenges of PKU and its multigenerational impact. The lessons learned from PKU may present the framework for developing programs that will provide services from infancy to adulthood for children with special health-care needs who are identified through newborn screening programs.

\section{References}

1. National Institutes of Health. Phenylketonuria. Screening and management. NIH Consensus Statement Online Available at: http://odp.od.nih.gov/consensus/cons/ 113/113_statement.htm. Accessed October 16-18, 2000.

2. Schuett VE, Gurda RF, Brown ES. Diet discontinuation policies and practices of PKU clinics in the United States. Am J Public Health 1980;70:498-503.

3. Waisbren SE, Schnell RR, Levy HL. Diet termination in children with phenylketonuria: a review of psychological assessments used to determine outcome. J Inherit Metab Dis 1980;3:149-153.

4. Koch R, Azen CG, Friedman EG, Williamson ML. Preliminary report on the effects of diet discontinuation in PKU. J Pediatr 1982;100:870-875.

5. Schuett VE, Brown ES. Diet policies of PKU clinics in the United States. Am J Public Health 1984;74:501-503.

6. Lenke RR, Levy HL. Maternal phenylketonuria and hyperphenylalaninemia: an international survey of the outcome of untreated and treated pregnancies. $N$ Engl J Med 1980;303:1202-1208.

7. Drogari E, Smith I, Beasley M, Lloyd JK. Timing of strict diet in relation to fetal damage in maternal phenylketonuria. Lancet 1987;2:927-930.

8. Smith I, Glossop J, Beasley M. Fetal damage due to maternal phenylketonuria: effects of dietary treatment and maternal phenylalanine concentrations around the time of conception. J Inherit Metab Dis 1990;13:651-657.

9. Guttler F, Lou H, Andresen J, Kok K, Mikkelsen I, Nielsen KB, Nielsen JB. Cognitive development in offspring of untreated and preconceptionally treated maternal phenylketonuria. J Inherit Metab Dis 1990;13:665-671.

10. Thompson GN, Francis DEM, Kirby DM, Compton R. Pregnancy in phenylketonuria: dietary treatment aimed at normalizing maternal phenylalanine concentration. Arch Dis Child 1991;66:1346-1349.

11. Platt LD, Koch R, Azen C, Hanley WB, Levy HL, Matalon R, Rouse B, de la Cruz F, Walla CA. Maternal phenylketonuria collaborative study, obstetric aspects and outcome: The first 6 years. Am J Obstet Gynecol 1992;166:1150-1162. 
12. Waisbren SE, Hanley W, Levy HL, Shifrin H, Allred E, Azen C, Chang PN, CipcicSchmidt S, de la Cruz F, Hall R, Matalon R, Nanson J, Rouse B, Trefz F, Koch R. Outcome at age 4 years in offspring of women with maternal phenylketonuria: the Maternal PKU Collaborative Study. JAMA 2000;283:756-762.

13. Friedman EG, Koch R, Azen C, Levy H, Hanley W, Matalon R, Rouse B, Trefz F, de la Cruz F. The International Collaborative Study on maternal phenylketonuria: organization, study design and description of the sample. Eur J Pediatr 1996; 155(suppl 1):S158-S161.

14. Platt LD, Koch R, Hanley WB, Levy HL, Matalon R, Rouse B, Trefx F, de la Cruz F, Guttler F, Azen C, Friedman EG. The international study of pregnancy outcome in women with maternal phenylketonuria: report of a 12-year study. Am J Obstet Gynecol 2000;182:326-333.

15. American College of Obstetrics, and Gynecology committee opinion. Maternal phenylketonuria. Committee on Genetics. Int J Gynaecol Obstet 2001;72:83-84.

16. Committee on Genetics, American Academy of Pediatrics. Maternal phenylketonuria. Pediatrics 2001;107:427-428.

17. Koch R, Levy HL, Matalon R, Rouse B, Hanley W, Azen C. The North American Collaborative Study of maternal phenylketonuria. Status Report 1993. Am J Dis Child 1993;147:1224-1230.
18. Luder AS, Greene CL. Maternal phenylketonuria and hyperphenylalaninemia: implications for medical practice in the United States. Am JObstet Gynecol 1989;161:1102-1105.

19. Kirkman HN. Projections of a rebound frequency of mental retardation from Phenylketonuria. Appl Res Ment Retard 1982;3:319-328.

20. Kirkman HN, Frazier DM. Maternal PKU: thirteen years after epidemiological projections. Int Pediatr 1996;11:279-283.

21. US Congress. Orphan Drug Amendments of 1988 (Act to Amend the Federal Food, Drug, Cosmetic Act to Revise the Provisions Respecting Orphan Drugs, for Other Purposes). Pub L No. 100-290. Washington, DC.

22. Millner BN. Insurance coverage of special foods needed in the treatment of phenylketonuria. Public Health Rep 1993;108:60-65.

23. Singh RH, Kable JA, Guerrero NV, Sullivan KM, Elsas LJ Jr. Impact of a camp experience on phenylalanine levels, knowledge, attitudes, and health beliefs relevant to nutrition management of phenylketonuria in adolescent girls. J Am Diet Assoc 2000;100:797-803.

24. Waisbren SE, Rokni H, Bailey I, Rohr F, Brown T, Warner-Rogers J. Social factors and the meaning of food in adherence to medical diets: results of a maternal phenylketonuria summer camp. J Inherit Metab Dis 1997;20:21-27.

25. St. James PS, Shapiro E, Waisbren SE. The Resource Mothers Program for maternal phenylketonuria. Am J Public Health 1999;89:762-764. 